\title{
Surface Modified Silicon Nitride Powder with Highly Dispersed Sintering Aid via Aqueous Processing
}

\author{
Yasuhiro SHIMIZU, Yasuo IKEDA, Takeo HYODO, Yuji TAKAO* and Makoto EGASHIRA \\ Department of Materials Science and Engineering, Faculty of Engineering, Nagasaki University, 1-14, Bunkyo-machi, Nagasaki-shi $852-8521$ \\ *Department of Environmental Studies, Faculty of Environmental Studies, Nagasaki University, 1-14, Bunkyo-machi, Nagasaki-shi $852-8521$
}

\section{水溶液系プロセスによる窒化ケイ素粉末表面への焼結助剂の高分散担持}

\author{
清水康博 ·池田靖生 ·兵頭健生·高尾雄二*·江頭＼cjkstart誠 \\ 長崎大学工学部材料工学科, 852-8521 長崎市文教町 1-14 \\ *長崎大学環境科学部環境科学科, 852-8521 長崎市文教町 1-14
}

\begin{abstract}
Highly dispersive loading of $\mathrm{Y}^{3+}$ ions, as a sintering aid, on $\mathrm{Si}_{3} \mathrm{~N}_{4}$ powder via aqueous processing has been presented. The chemical stability of $\mathrm{Si}_{3} \mathrm{~N}_{4}$ powder in pressured and saturated water vapor was improved by a chemical surface modification with dicarboxylic sebacic acid, while maintaining hydrophilic surface. The treatment of the sebacic acid-modified powder with yttrium acetate tetrahydrate resulted in strong immobilization of $\mathrm{Y}^{3+}$ ions at a highly dispersive level on the $\mathrm{Si}_{3} \mathrm{~N}_{4}$ powder surface through ion-exchange with the free carboxyl groups of the sebacic acid molecules attached to the $\mathrm{Si}_{3} \mathrm{~N}_{4}$ surface. The highly dispersive sintering aid promoted hot-press densification of $\mathrm{Si}_{3} \mathrm{~N}_{4}$ even with a small loading amount, in comparison with materials added with $\mathbf{Y}_{2} \mathbf{O}_{3}$ powder as a sintering aid. $\quad$ [Received January 5, 2000; Accepted June 21, 2000]
\end{abstract}

Key-words : Silicon nitride, Sintering aid, Ion-exchange, $Y^{3+}$ ions, Surface modification, Densification

\section{Introduction}

Silicon nitride ceramics are among the most promising materials for high-temperature structural applications because of their combination of properties, including roomand elevated-temperature strength, toughness, oxidation stability, low coefficient of thermal expansion, and low density relative to refractory metals. ${ }^{1)-4)}$ The fabrication of the $\mathrm{Si}_{3} \mathrm{~N}_{4}$ ceramics with high reliability of the thermomechanical properties essentially depends on densities and both physical and chemical homogeneities of green compacts. ${ }^{5}$ ) The ceramics are usually fabricated by liquid-phase sintering, with or without pressure, of the compacts composed of a mixture of silicon nitride and sintering aid powders, such as $\mathrm{Y}_{2} \mathrm{O}_{3}, \mathrm{MgO}$ and $\mathrm{Al}_{2} \mathrm{O}_{3}$. Besides microstructural heterogeneities associated with particle size distribution of raw powders, in such systems consisting of oxide and non-oxide particles, segregation of sintering aid powders may occur in the green compacts due to great differences in the surface chemical properties of the different powder components. Such an inhomogeneity remains or is enhanced during the sintering process, and then limits the manufacture of ceramics with excellent properties. Homogeneous precipitation of sintering aids on $\mathrm{Si}_{3} \mathrm{~N}_{4}$ powders have been demonstrated by an in situ sol-gel process ${ }^{6)}$ and a solution-based method using nitrate. ${ }^{7)}$

Recently, optimization of aqueous $\mathrm{Si}_{3} \mathrm{~N}_{4}$ slurries including the choice of molecules to be chemisorbed on the powder, dispersants and binders has been investigated extensively.4),8),9) This is because the slip casting is a suitable consolidation process to obtain high densities of green compacts and subsequent highly sintered densities. It has been revealed that the chemisorbed molecules, such as silanes with diamino and poly (ethylene glycol) hydrophilic heads, are useful for not only achieving slurries with highest packing density, but also suppressing reactivity of $\mathrm{Si}_{3} \mathrm{~N}_{4}$ powder with water. ${ }^{4)}$ Although the oxidation and/or hydration kinetics of $\mathrm{Si}_{3} \mathrm{~N}_{4}$ powder is extremely slower than those of AlN powder, ${ }^{10)}-12$ ) the progress of the reactions yielded an increase in the oxygen contents and hence requires the adjustment of the additive amounts of sintering aids so that an improvement of densification can be achieved. ${ }^{3)}$ Even though the slip casting is also useful for obtaining microstructural homogeneity of green compacts, special attentions are needed for the selection of surfactants and dispersants so as to achieve homogenous mixing of $\mathrm{Si}_{3} \mathrm{~N}_{4}$ and sintering aid powders.

Our previous study has demonstrated that surface modification of AlN powder with sebacic acid having two carboxylic heads yields a water-resistant nature, while maintaining hydrophilic surface suitable for aqueous colloidal processing, i.e., slip casting. ${ }^{13)}$ The aim of the present study was first directed to surface chemical modification of $\mathrm{Si}_{3} \mathrm{~N}_{4}$ powder with sebacic acid so that both a water-resistant nature and hydrophilic surface could be achieved, in analogy with the surface modification of AlN powder developed. Furthermore, highly homogeneous distribution of a sintering aid was conducted by chemisorption of yttrium acetate derivatives on $\mathrm{Si}_{3} \mathrm{~N}_{4}$ powder through the sebacic acid, so as to achieve an improvement of densification of ceramics. Microstructure of $\mathrm{Si}_{3} \mathrm{~N}_{4}$ ceramics fabricated by this improved process was compared with that of $\mathrm{Si}_{3} \mathrm{~N}_{4}$ ceramics fabricated by a conventional method by employing a mixture of $\mathrm{Si}_{3} \mathrm{~N}_{4}$ and $\mathrm{Y}_{2} \mathrm{O}_{3}$ powders.

\section{Experimental procedure}

2.1 Chemical surface modification of $\mathrm{Si}_{3} \mathrm{~N}_{4}$ powder The $\mathrm{Si}_{3} \mathrm{~N}_{4}$ powder used was SN-9FWS $\left(\alpha-\mathrm{Si}_{3} \mathrm{~N}_{4}, 90\right.$ mass $\%>$ ) produced carbothermally by Denki Kagaku Kogyo K.K., with surface area of $12.0 \mathrm{~m}^{2} / \mathrm{g}$. The powder was treated in vacuo at $150^{\circ} \mathrm{C}$ for $3 \mathrm{~h}$ to remove physically adsorbed water that might exist on the surface, and was subsequently subjected to chemical surface modification with sebacic acid, $\mathrm{HOOC}\left(\mathrm{CH}_{2}\right)_{8} \mathrm{COOH}(97 \%$, Wako Pure Chemical Industries, Ltd.). The amount of sebacic acid used for the modification was $1.61 \times 10^{-1} \mathrm{~mol}$ per mol of $\mathrm{Si}_{3} \mathrm{~N}_{4}$. This amount corresponded to ten times that of $\mathrm{Si}$ atoms at the surface calculated from its surface area and assuming the $\mathrm{Si}_{3} \mathrm{~N}_{4}$ surface to consist of only (001) planes. The $\mathrm{Si}_{3} \mathrm{~N}_{4}$ powder was mixed with sebacic acid in a three-neck reaction flask, by employing dehydrated benzene as a solvent, and 
then the suspension was refluxed around $80^{\circ} \mathrm{C}$ for $3 \mathrm{~h}$. After the similar treatment of AlN powder conduced in our previous study, we have found new adsorption bands at 1588 and $1470 \mathrm{~cm}^{-1}$ which could be attributed to asymmetric and symmetric stretching of $\mathrm{COO}$ bonded to $\mathrm{Al}$ by FT-IR spectroscopic analysis. ${ }^{13)}$ From thermodynamic consideration, $\mathrm{Si}_{3} \mathrm{~N}_{4}$ is likely oxidized to silica or silicon oxynitride, ${ }^{14)}$ and in turn its surface is certainly covered with hydroxyl groups in an ambient atmosphere. Thus, the following dehydration-condensation reaction was expected to progress during the treatment of $\mathrm{Si}_{3} \mathrm{~N}_{4}$ powder, in a manner similar to the surface modification of AlN powder.

$$
\begin{aligned}
& \mathrm{Si}-\mathrm{OH}+\mathrm{HOOC}-\mathrm{R}-\mathrm{COOH} \\
& \longrightarrow \mathrm{Si}-\mathrm{O}-\mathrm{C}-\mathrm{R}-\mathrm{COOH}+\mathrm{H}_{2} \mathrm{O}
\end{aligned}
$$

The modified $\mathrm{Si}_{3} \mathrm{~N}_{4}$ powder was washed with different kinds of organic solvents to remove excess sebacic acid under the same condition: organic solvents of $100 \mathrm{ml}$ per the modified $\mathrm{Si}_{3} \mathrm{~N}_{4}$ powder of $1.0 \mathrm{~g}$. The powder was filtrated and then was dried in vacuo at $150^{\circ} \mathrm{C}$ for $3 \mathrm{~h}$.

The amount of sebacic acid chemisorbed on $\mathrm{Si}_{3} \mathrm{~N}_{4}$ and its oxidation behavior before and after the washing were studied by TG-DTA (DTG-50, Shimadzu) up to $800^{\circ} \mathrm{C}$ at a heating rate of $10^{\circ} / \mathrm{min}$ under flowing air at $100 \mathrm{ml} / \mathrm{min}$. For comparative purpose, the surface chemical modification with stearic acid, typical monocarboxylic acid, was also conducted in a manner similar to that described above.

2.2 Measurement of chemical stability of $\mathrm{Si}_{3} \mathrm{~N}_{4}$ powders in water

As-received and sebacic acid-modified $\mathrm{Si}_{3} \mathrm{~N}_{4}$ powders were treated under a pressured and saturated water vapor environment (pressure cooker test, PCT), as follows. Deionized water of $30 \mathrm{ml}$ was poured into a Teflon vessel (volume: $60 \mathrm{~cm}^{3}$ ), and the powder of $1.0 \mathrm{~g}$ was suspended over the water by using an open glass holder. The vessel was put on the Teflon lid and then was closed up tight in a stainless steel vessel. The vessel was kept at $121^{\circ} \mathrm{C}$ for $24 \mathrm{~h}$. The amount of hydrolyzed $\mathrm{Si}_{3} \mathrm{~N}_{4}$ was calculated from the $\mathrm{pH}$ change of the deionized water in the vessel. The chemical stability against pressured and saturated water vapor was evaluated by the hydrolyzed amount. The chemical stability was further confirmed by examining the powders by XRD (2807C3, Rigaku Corp.) after PCT.

2.3 Loading of a sintering aid by a solution-based method

Chemisorption of yttrium acetate tetrahydrate was conducted as follows: the sebacic acid-modified $\mathrm{Si}_{3} \mathrm{~N}_{4}$ powder was washed with methanol, the washed powder of 10-50 g was dispersed in an aqueous solution of $200-500 \mathrm{ml}$ of yttrium acetate tetrahydrate (Wako Pure Chemical Industries, Ltd.) at concentrations of $2.25-3.0 \mathrm{~mol} / 1$, and the suspension was stirred at $25^{\circ} \mathrm{C}$ for $24 \mathrm{~h}$. The powder was filtered off and then was dried in vacuo at $50^{\circ} \mathrm{C}$ for $3 \mathrm{~h}$. Besides weakly attracted yttrium acetate, we expected ion-exchange reactions between yttrium acetate derivatives and protons in the free carboxylic groups at the sebacic acid-modified $\mathrm{Si}_{3} \mathrm{~N}_{4}$ powder surface during this treatment, and then strong immobilization of $\mathrm{Y}^{3+}$ ions on the modified powder at a highly dispersive level, as expressed by such a following equation.

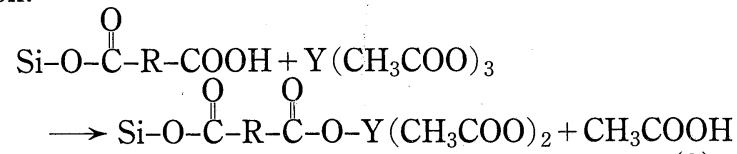

Thereafter, the powder was washed with deionized water and filtered off. The washing repeated until no yttrium ions could be detected in the filtrate. The $\mathrm{Y}^{3+}$-chemisorbed $\mathrm{Si}_{3} \mathrm{~N}_{4}$ powders before and after the washing were immersed in a hydrochloric acid solution, and then the solution containing the eluted $\mathrm{Y}^{3+}$ ions was titrated with EDTA to determine the concentrations of chemisorbed $\mathrm{Y}^{3+}$ ions. The $\mathrm{Y}^{3+}$ chemisorbed $\mathrm{Si}_{3} \mathrm{~N}_{4}$ powders were also subjected to the TG-DTA measurements up to $800^{\circ} \mathrm{C}$ to determine the weight changes associated with the combustion of organic components and the oxidation of $\mathrm{Y}^{3+}$ ions to $\mathrm{Y}_{2} \mathrm{O}_{3}$. The total weight of organic components in the $\mathrm{Y}^{3+}$-chemisorbed $\mathrm{Si}_{3} \mathrm{~N}_{4}$ powders could be calculated from both the concentrations of chemisorbed $\mathrm{Y}^{3+}$ ions and the weight changes, and hence the loading amounts of the sintering aid as $\mathrm{Y}_{2} \mathrm{O}_{3}$ could be determined.

\subsection{Fabrication of $\mathrm{Si}_{3} \mathrm{~N}_{4}$ ceramics}

The $\mathrm{Y}^{3+}$-chemisorbed $\mathrm{Si}_{3} \mathrm{~N}_{4}$ powder without washing was used for fabricating ceramics in this study, since the titration and the TG-DTA measurements revealed the decrease in the amount of $\mathrm{Y}^{3+}$ ions after washing down to about 0.6 mass $\%$ as $\mathrm{Y}_{2} \mathrm{O}_{3}$, as described later. The powder was fired at $600^{\circ} \mathrm{C}$ for $1 \mathrm{~h}$ in air to burn out the organic components prior to sintering. The powder was then placed into a graphite die and hot-pressed at $1750^{\circ} \mathrm{C}$ for $1.5 \mathrm{~h}$ at a heating rate of $15^{\circ} /$ min, under a uniaxial pressure of $50 \mathrm{MPa}$ in a flowing $\mathrm{N}_{2}$ atmosphere (FT-50/200, Fujidempa Kogyo Co., Ltd.). The surfaces of the hot-pressed ceramics were polished with emery paper. The ceramics fabricated are typically $25 \times 25$ $\times 25 \mathrm{~mm}$ in size.

$\mathrm{Si}_{3} \mathrm{~N}_{4}$ ceramics were also fabricated by employing $\mathrm{Y}_{2} \mathrm{O}_{3}$ powder (average particle size: $2.5 \mu \mathrm{m}, 99.99 \%$, Kishida Reagents Chemicals) as a sintering aid for comparative purpose. The mixture of as-received $\mathrm{Si}_{3} \mathrm{~N}_{4}$ and 5.0 mass $\% \mathrm{Y}_{2} \mathrm{O}_{3}$ powder was milled for $12 \mathrm{~h}$ in a ball mill using methanol and YTZ (yttria-toughened zirconia) balls (Nikkato Corp.) as grinding media. The mixture was then subjected to the same prefiring and sintering conditions.

\subsection{Characterization of $\mathrm{Si}_{3} \mathrm{~N}_{4}$ ceramics}

Density of $\mathrm{Si}_{3} \mathrm{~N}_{4}$ ceramics was determined by the Archimedes method. Fracture sections of the ceramics were polished with diamond paste, and then subjected to Ar plasma bombardment for 4 min, followed by treatment with 46 $\% \mathrm{HF}$ and $35 \% \mathrm{HCl}$ solution for $10 \mathrm{~min}$ and $5 \mathrm{~min}$, respectively. Thereafter, the etched surface was observed by SEM (S-2250N, Hitachi Ltd.).

\section{Results and discussion}

\subsection{Chemisorption and oxidation behavior of sebacic} acid on $\mathrm{Si}_{3} \mathrm{~N}_{4}$

Figure 1 (b) shows TG-DTA curves obtained with the sebacic acid-modified $\mathrm{Si}_{3} \mathrm{~N}_{4}$ powder before washing. A slight weight loss was observed up to around $150^{\circ} \mathrm{C}$, and an abrupt and large decrease in weight was observed at $200-250^{\circ} \mathrm{C}$, while two endothermic peaks and one exothermic peak appeared around 135,250 and $325^{\circ} \mathrm{C}$, respectively. For comparative purpose, TG-DTA curves obtained with asreceived and stearic acid-modified $\mathrm{Si}_{3} \mathrm{~N}_{4}$ powder were shown in Figs. 1(a) and 1(c), respectively. The as-received powder exhibited a slight decrease in weight up to around $450^{\circ} \mathrm{C}$, probably due to the desorption of physisorbed water and hydroxyl groups on the surface. In the case of the stearic acid-modified powder, on the other hand, weight loss was negligible up to around $170^{\circ} \mathrm{C}$, beyond that a slight decrease in weight was observed up to around $450^{\circ} \mathrm{C}$. A large exothermic peak appeared around $300^{\circ} \mathrm{C}$. Thus, both the weight loss and the exothermic peak were due to the oxidation of chemisorbed stearic acid. The surface coverage of chemisorbed stearic acid was calculated to be $93 \%$ from the weight loss, assuming again the surface to consist of only (001) planes and stearic acid to be chemisorbed (by the dehydration-condensation reaction) on only one third of the surface $\mathrm{Si}$ atoms due to the steric hindrance of carboxylic 
acid (see Fig. 2). The little weight loss up to around $170^{\circ} \mathrm{C}$ implies the absence of hydroxyl groups and/or physisorbed water due to its hydrophobic nature of the stearic acid-modified $\mathrm{Si}_{3} \mathrm{~N}_{4}$ powder from the analogy to the stearic acid-modified AlN powder reported previously. ${ }^{15)}$

From the large weight loss observed in Fig. 1(b), the surface coverage of sebasic acid on the surface was calculated to be $837 \%$ by the same assumption, suggesting the existence of a large amount of weakly attracted sebacic acid by hydrogen bonds to the chemisorbed sebacic acid fixed by the dehydration-condensation reaction, as schematically shown in Fig. 3(b). Such a change in weight loss between stearic acid- and sebacic acid-modified powder may be ascribed to the difference in surface nature: hydrophobic for

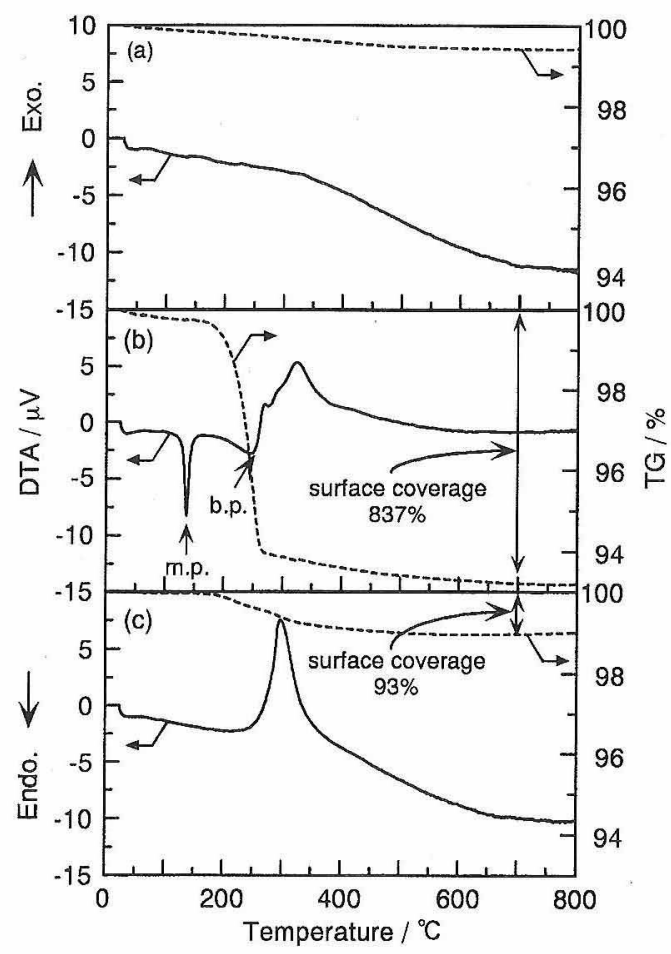

Fig. 1. TG-DTA curves obtained with (a) as-received, (b) sebacic acid-modified, and (c) stearic acid-modified $\mathrm{Si}_{3} \mathrm{~N}_{4}$ powder. the stearic acid-modified $\mathrm{Si}_{3} \mathrm{~N}_{4}$ and hydrophilic for the sebacic acid-modified one due to the existence of free carboxylic group heads. Therefore, the slight weight loss up to around $150^{\circ} \mathrm{C}$ observed in Fig. 1 (b) can be ascribed to the desorption of physisorbed water. In addition, it can be considered that two endothermic peaks around 135 and $250^{\circ} \mathrm{C}$ stands for melting and boiling of the weakly attracted sebacic acid (the melting and boiling point of sebacic acid are 134 and $232^{\circ} \mathrm{C}$, respectively). The $837 \%$ surface coverage of sebacic acid was too large to be subjected to the loading of a sintering aid by the subsequent ion-exchange reaction. Therefore, the sebacic acid-modified $\mathrm{Si}_{3} \mathrm{~N}_{4}$ was washed with several organic solvents prior to the ion-exchange reaction.

3.2 Surface coverage of sebacic acid and chemical stability of sebacic-acid modified $\mathrm{Si}_{3} \mathrm{~N}_{4}$ after washing with organic solvents

Figure 4 shows TG-DTA curves obtained with sebacic acid-modifed $\mathrm{Si}_{3} \mathrm{~N}_{4}$ after washing with several organic solvents. By the washing, surface coverage of sebacic acid calculated from the weight loss decreased significantly: the efficiency of detergents was in the order of 1-propanol< methanol $<$ ethanol $<$ acetone. In accordance with this order, the height of two endothermic peaks decreased. On the

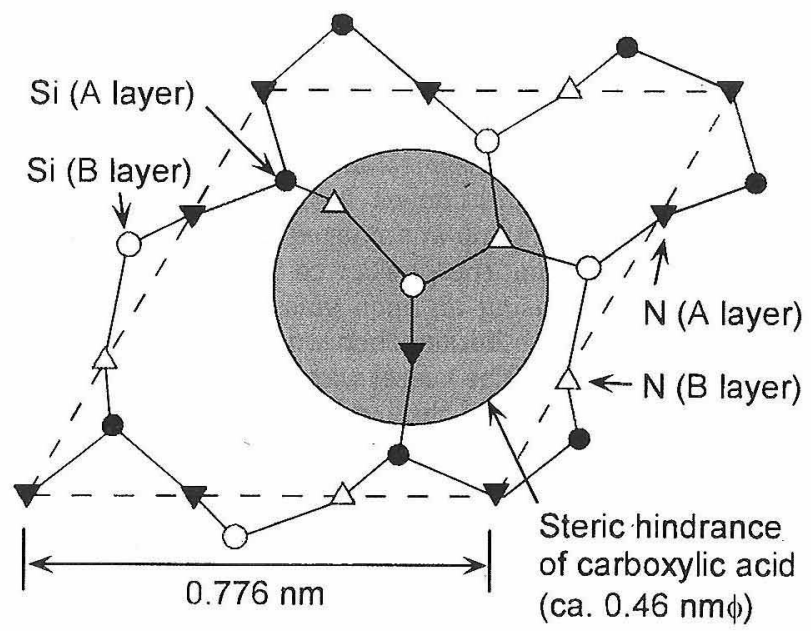

Fig. 2. Surface structure of $\alpha-\mathrm{Si}_{3} \mathrm{~N}_{4}$ and steric hindrance of carboxylic acid chemisorbed on an Si metal on the surface.

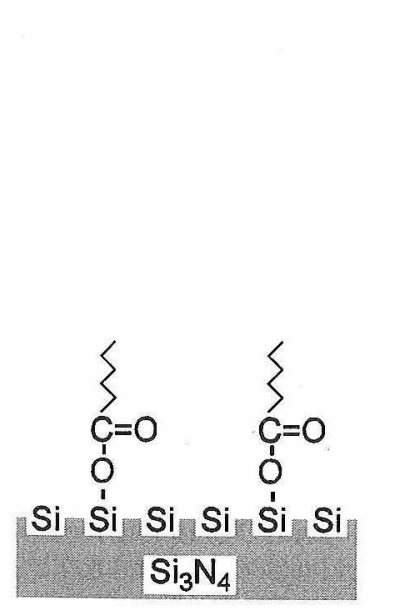

(a)

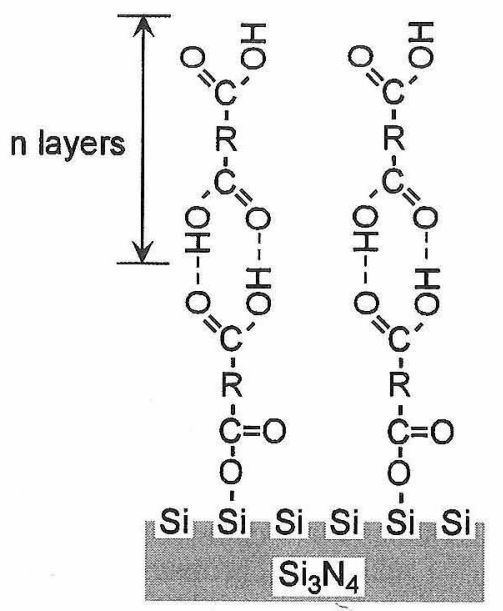

(b)

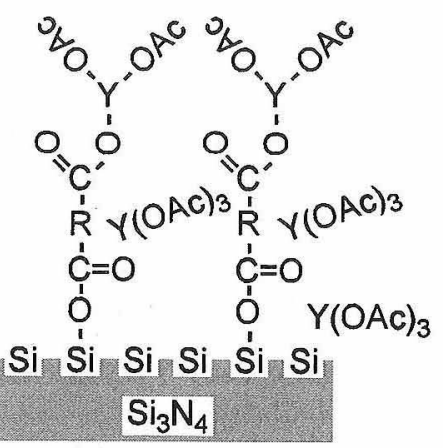

(c)

Fig. 3. Schematic drawings of (a) stearic acid-, (b) sebacic acid-modified, and (c) $\mathrm{Y}^{3+}$-chemisorbed $\mathrm{Si}_{3} \mathrm{~N}_{4}$ powder surface. 


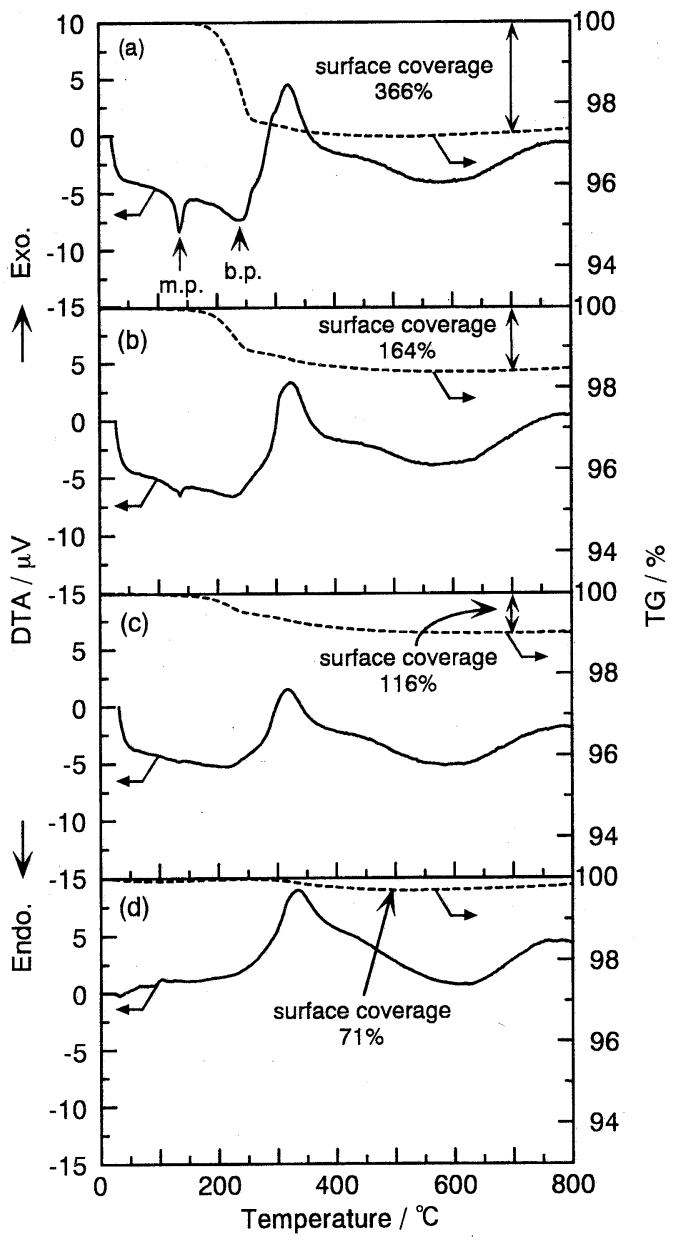

Fig. 4. TG-DTA curves obtained with sebacic acid-modified $\mathrm{Si}_{3} \mathrm{~N}_{4}$ powder after washing with (a) 1-propanol, (b) ethanol, (c) methanol and (d) acetone.

other hand, the height of the exothermic peak remained almost unchanged, irrespective of the kind of organic detergents. This implies that the amount of sebacic acid fixed by the dehydration-condensation reaction is not affected by the subsequent washing, whereas weakly attached sebacic acid can be removed effectively by the washing.

Table 1 summarizes the chemical stability of the sebacic acid-modified $\mathrm{Si}_{3} \mathrm{~N}_{4}$ with and without washing during PCT. When as-received $\mathrm{Si}_{3} \mathrm{~N}_{4}$ powder was immersed in deionized water at $50^{\circ} \mathrm{C}$ for $5 \mathrm{~h}$, its hydrolysis was negligible, since no $\mathrm{pH}$ changes of the water were detected and XRD of the powder after the immersion revealed no phases other than $\mathrm{Si}_{3} \mathrm{~N}_{4}$. Under pressured and saturated water vapor at $121^{\circ} \mathrm{C}$ for $24 \mathrm{~h}$, however, it was revealed that 5.0 mass $\%$ of $\mathrm{Si}_{3} \mathrm{~N}_{4}$ was hydrolyzed. The water-resistant nature of $\mathrm{Si}_{3} \mathrm{~N}_{4}$ was improved by the modification with sebacic acid, i.e., only 0.20 mass $\%$ of $\mathrm{Si}_{3} \mathrm{~N}_{4}$ was hydrolyzed in the case of sebacic acidmodified powder without washing. The washing with organic solvents also yielded the improved water-resistant nature, though the hydrolysis amount increased slightly after washing with acetone. From the results summarized in Table 1, it is suggested that the excess sebacic acid on $\mathrm{Si}_{3} \mathrm{~N}_{4}$ powder is not necessary for improving the water-resistant nature nor for promoting the ion-exchange reaction with yttrium acetate tetrahydrate. Thus, the sebacic acid-modified $\mathrm{Si}_{3} \mathrm{~N}_{4}$ washed with methanol was subjected to the following ionexchange reaction aimed at loading of $\mathrm{Y}^{3+}$ ions in a high dispersive level. The results summarized in Table 1 also con-
Table 1. Surface Coverage of Sebacic Acid and Chemical Stability of the Modified $\mathrm{Si}_{3} \mathrm{~N}_{4}$ after Washing with Several Organic Solvents

\begin{tabular}{lrcc}
\hline Specimen & Detergent & $\begin{array}{c}\text { Surface coverage } \\
\text { of sebacic acid } \\
(\%)\end{array}$ & $\begin{array}{c}\text { Amount of } \\
\text { hydration } \\
(\%)\end{array}$ \\
\hline As-received & none & 0 & 5.0 \\
Modified & none & 837 & 0.20 \\
& 1-propanol & 366 & 0.20 \\
& ethanol & 164 & 0.18 \\
methanol & 116 & 0.20 \\
& acetone & 71 & 0.71 \\
\hline
\end{tabular}

a) during PCT at $121^{\circ} \mathrm{C}$ for $24 \mathrm{~h}$.

Table 2. Effect of Washing on Loading Amounts of a Sintering Aid after Ion-Exchange Reaction

\begin{tabular}{cc}
\hline $\begin{array}{c}\text { The number of } \\
\text { times of washing }\end{array}$ & $\begin{array}{c}\text { Loading amount } \\
\text { as } \mathrm{Y}_{2} \mathrm{O}_{3} \text { (mass\%) }\end{array}$ \\
\hline 0 & 3.4 \\
2 & 0.67 \\
3 & 0.64 \\
\hline
\end{tabular}

firms the progress of the dehydration-condensation reaction during the modification with sebacic acid, though the surface analysis of the sebacic acid-modified $\mathrm{Si}_{3} \mathrm{~N}_{4}$ powder was not conducted by FT-IR in the present study.

3.3 Effect of washing on the loading amount of $\mathrm{Y}^{3+}$ ions after ion-exchange reaction

The sebacic-acid modified $\mathrm{Si}_{3} \mathrm{~N}_{4}$ powder (washed with methanol) of $40 \mathrm{~g}$ was treated in an aqueous solution of 400 $\mathrm{ml}$ of yttrium acetate tetrahydrate at a concentration of 3.0 $\mathrm{mol} / 1$ at $25^{\circ} \mathrm{C}$ for $24 \mathrm{~h}$. The powder was filtered off and then was dried in vacuo at $50^{\circ} \mathrm{C}$ for $3 \mathrm{~h}$. The powder was subsequently washed with water, as described in the experimental section. Table 2 summarizes the amounts of the sintering aid as $\mathrm{Y}_{2} \mathrm{O}_{3}$ after different times of washing. A loading amount of 0.34 mass $\%$ was calculated, by assuming the surface of $\mathrm{Si}_{3} \mathrm{~N}_{4}$ to consist of only (001) planes, sebacic acid to be chemisorbed on only one third of the surface $\mathrm{Si}$ atoms, and protons in the free carboxylic groups of chemisorbed sebacic acid to be exchanged with $\mathrm{Y}\left(\mathrm{CH}_{3} \mathrm{COO}\right)_{2}{ }^{+}$(see Eq. (2)). The loading amount of $\mathrm{Y}_{2} \mathrm{O}_{3}$ for the $\mathrm{Y}^{3+}$-chemisorbed powder without washing was about ten times as large as that of the calculated value, suggesting the existence of a large amount of yttrium acetate attached weakly on the surface as well as the chemisorbed sebacic acid (see Fig. 3 (c)). Washing with water still yielded about twice as much as the calculated value, but the loading amount of $\mathrm{Y}_{2} \mathrm{O}_{3}$ was considered to be low so as to promote densification of $\mathrm{Si}_{3} \mathrm{~N}_{4}$. Therefore, the $\mathrm{Y}^{3+}$-chemisorbed powder without washing was subjected to sintering in the below. It should be noted that the loading amount of $\mathrm{Y}_{2} \mathrm{O}_{3}$ varied slightly with the ionexchange conditions: the amount of sebacic acid-modified powder and the concentration of aqueous solutions of yttrium acetate tetrahydrate used.

\subsection{Microstructure of $\mathrm{Si}_{3} \mathrm{~N}_{4}$ ceramics}

Table 3 summarizes relative density of $\mathrm{Si}_{3} \mathrm{~N}_{4}$ ceramics prepared from the $\mathrm{Y}^{3+}{ }_{-}$-chemisorbed $\mathrm{Si}_{3} \mathrm{~N}_{4}$ powders. For comparative purpose, relative density of the $\mathrm{Si}_{3} \mathrm{~N}_{4}$ ceramics prepared from the mixture of as-received $\mathrm{Si}_{3} \mathrm{~N}_{4}$ and 5.0 mass $\% \mathrm{Y}_{2} \mathrm{O}_{3}$ powder is also listed in Table 3 . The loading of the sintering aid by the ion-exchange reaction was found to 
Table 3. Relative Density of $\mathrm{Si}_{3} \mathrm{~N}_{4}$ Ceramics Fabricated by HotPressing

\begin{tabular}{|c|c|c|c|}
\hline No. & $\begin{array}{l}\text { Sintering } \\
\text { aid }\end{array}$ & $\begin{array}{c}\text { Amount of } \\
\mathrm{Y}_{2} \mathrm{O}_{3} \\
\text { (mass\%) }\end{array}$ & $\begin{array}{r}\text { Relative } \\
\text { density } \\
\left(\mathrm{g} / \mathrm{cm}^{3}\right)\end{array}$ \\
\hline |-1 & Chemisorbed $Y^{3+}$ & 0.71 & 94.7 \\
\hline $1-3$ & Chemisorbed $Y^{3+}$ & 3.3 & 98.8 \\
\hline $1-6$ & Chemisorbed $Y^{3+}$ & 5.7 & 97.1 \\
\hline P-5 & $\mathrm{Y}_{2} \mathrm{O}_{3}$ & 5.0 & 91.0 \\
\hline
\end{tabular}

promote the densification even in a small loading amount of $\mathrm{Y}_{2} \mathrm{O}_{3}$ as low as 0.71 mass $\%$. In addition, the relative density reached $97.1 \%$ when the $\mathrm{Y}^{3+}$-chemisorbed powder contained 5.7 mass $\%$ of the sintering aid as $\mathrm{Y}_{2} \mathrm{O}_{3}$, whereas the relative density was $91.0 \%$ at most when 5.0 mass $\% \mathrm{Y}_{2} \mathrm{O}_{3}$ powder was used as a sintering aid. Indeed, a large volume of pores was found in the etched fracture surface of the latter ceramics, as shown in Fig. 5. Thus, it is revealed that the highly dispersed sintering aid is very likely to have promoted densification of $\mathrm{Si}_{3} \mathrm{~N}_{4}$ grains.

The method proposed in the present study, i.e., the surface modification with dicarboxylic acids based on the dehydaration-condensation reaction followed by the ion-exchange reaction with metal acetates, offers the potential for high dispersion of not only $\mathrm{Y}^{3+}$ ions but also $\mathrm{Al}^{3+}$ or $\mathrm{Mg}^{2+}$ ions on $\mathrm{Si}_{3} \mathrm{~N}_{4}$ powder. Such sintering aid-dispersed $\mathrm{Si}_{3} \mathrm{~N}_{4}$ powder may allow us to fabricate high density and compositional homogeneity of green compacts by aqueous colloidal processing, i.e., slip casting, and hence ceramics with high reliability of the thermomechanical properties. Furthermore, the amount of sintering aids necessary for achieving the densification of $\mathrm{Si}_{3} \mathrm{~N}_{4}$ may be reduced by this ion-exchange loading method and subsequent aqueous colloidal processing.

\section{Conclusions}

The chemical stability of $\mathrm{Si}_{3} \mathrm{~N}_{4}$ powder in pressured and saturated water vapor was improved by the chemical surface modification with sebacic acid. High dispersion of $\mathrm{Y}^{3+}$ ions as a sintering aid could be achieved by the treatment of the sebacic acid-modified powder with yttrium acetate tetrahydrate. Although the $\mathrm{Y}^{3+}$-chemisorbed powder required a prefiring process to burn out the organic components, the highly dispersed sintering aid promoted the densification of $\mathrm{Si}_{3} \mathrm{~N}_{4}$ even with a small loading amount, in comparison with the addition of $\mathrm{Y}_{2} \mathrm{O}_{3}$ powder as a sintering aid, by hot-pressing.

Acknowledgments The present study was partly supported by a Grant-in-Aid for Scientific Research (B) (No. 1055219) from the Ministry of Education, Science, Sports and Culture of Japan. Many thanks and appreciation go to Denki Kagaku Kogyo K.K. for supplying the $\mathrm{Si}_{3} \mathrm{~N}_{4}$ powder.

\section{References}

1) H. Park, H.-W. Kim and H.-E. Kim, J. Am. Ceram. Soc., 81, 2130-34 (1998)

2) H. Gu, X. Pan, R. M. Cannon and M. Rühle, J. Am. Ceram. Soc., 81, 3125-35 (1998).

3) A. W. Weimer, D. F. Carroll, D. W. Susnitzky and D. R. Bea-
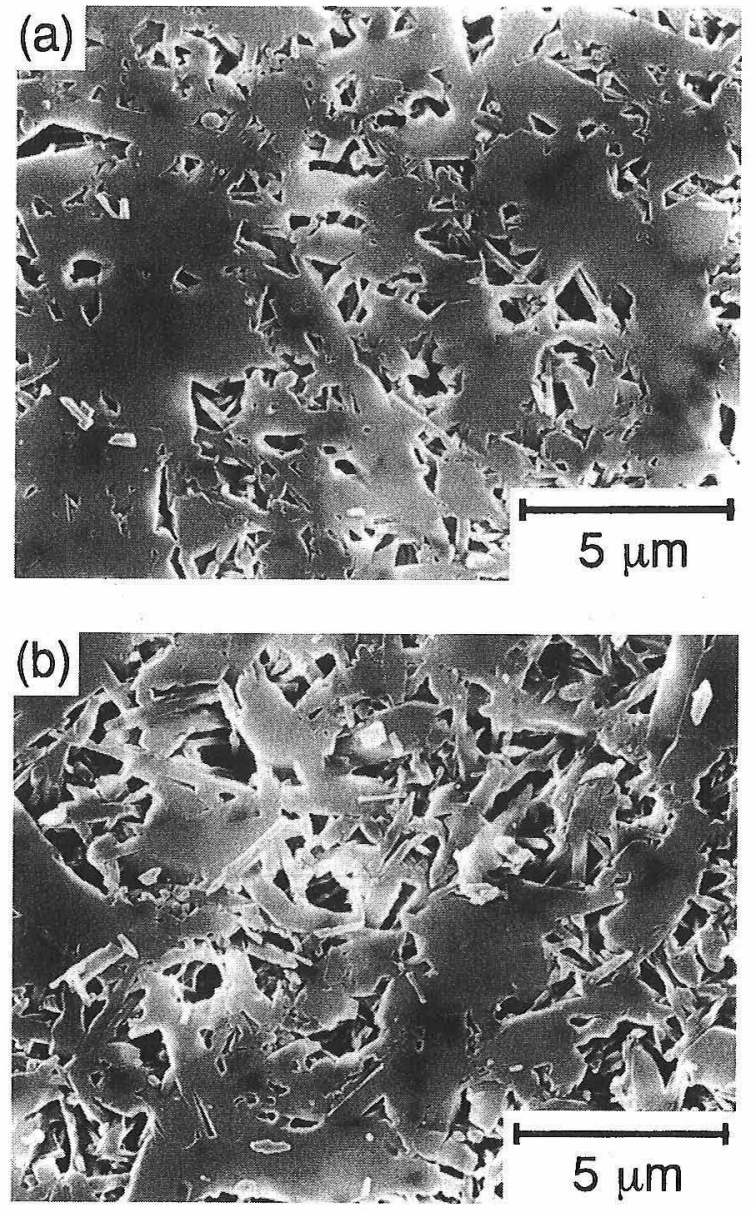

Fig. 5. Scanning electron micrographs of the fracture surface of (a) No. I-6 and (b) No. P-5 in Table 3 .

man, J. Am. Ceram. Soc., 82, 1635-38 (1999)

4) M. Colic, G. Franks, M. Fisher and F. Lange, J. Am. Ceram. Soc., 81, 2157-63 (1998).

5) M. N. Rahaman, Y. Boiteux and L. C. De Jonghe, Am. Ceram. Soc. Bull., 65, 1171-76 (1986).

6) M. Kulig and P. Greil, J. Mater. Sci., 26, 216-24 (1991)

7) J. Kim, T. Iseki and T. Yano, J. Ceram. Soc. Japan, 105, 147-51 (1997) [in Japanese].

8) M. P. Albano and L. B. Garrido, J. Am. Ceram. Soc., 81, 837-44 (1998).

9) U. Paik, V. A. Hackley and H.-W. Lee, J. Am. Ceram. Soc., 82, 833-40 (1999).

10) P. Bowen, J. G. Highfield, A. Mocellin and T. A. Ring, J. Am. Ceram. Soc., 73, 724-28 (1990).

11) M. Egashira, Y. Shimizu and S. Takatsuki, J. Mater. Sci. Lett. 10, 994-96 (1991).

12) N. Saito and K. Ishizaki, J. Am. Ceram. Soc., 79, 1213-17 (1996).

13) Y. Shimizu, K. Kawanabe, Y. Taki, Y. Takao and M. Egashira, "Ceramic Processing Science and Technology, Ceramic Transactions," Vol. 51, Ed. by H. Hausner, G. L. Messing and S. Hirano, Am. Ceram. Soc., Westerville, Ohio (1995) pp. 403-07.

14) M. Peuckert and P. Greil, J. Mater. Sci., 22, 3717-20 (1987).

15) M. Egashira, Y. Shimizu, Y. Takao, R. Yamaguchi and Y. Ishikawa, J. Am. Ceram. Soc., 77, 1793-98 (1994). 